\title{
Renal Tubular Protein Absorption in the Rat
}

\author{
Marshall A. Cortney, Linda L. Sawin, and Dennis D. Weiss \\ From the Department of Physiology and Biophysics, University of Iowa, \\ Iowa City, Iowa 52240
}

\begin{abstract}
A B S T R A C T Radioiodinated protein solutions, $20 \mathrm{nl}$ in volume, were injected into surface proximal and distal convoluted tubules of the rat kidney. The unabsorbed fraction was collected in ureteral urine, and the percentage recovered was expressed as a function of the injection site. Recovery increased progressively from more distal sites of injection indicating absorption along the proximal tubule of human serum albumin, insulin, and ribonuclease. Fractional absorption of albumin along the proximal tubule varied from 0 to $20 \%$ of the injected load, and was similar when the injectate concentration was 20,40 , or $100 \mathrm{mg} / 100 \mathrm{ml}$. Fractional absorption along the proximal tubule of insulin and ribonuclease, smaller proteins, was 30 to $50 \%$ of the injected load, and was similar with insulin concentrations of $0.09 \mathrm{mg} / 100 \mathrm{ml}$ and $40 \mathrm{mg} / 100 \mathrm{ml}$ and ribonuclease concentration of $40 \mathrm{mg} / 100 \mathrm{ml}$. In addition to this constant fractional absorption of each protein in the proximal tubule, smaller amounts were absorbed when injections were made in distal convoluted tubules.
\end{abstract}

\section{INTRODUCTION}

The accepted view of the fate of protein in the kidney is that some passage of all but the largest molecules occurs across the glomerulus and most of this is absorbed along the nephron. In previous micropuncture experiments no progressive protein concentration changes were noted along the nephron, and in the dog the concentrations ranged from 0 to $15 \mathrm{mg} / 100 \mathrm{ml}$ (1). Protein administered parenterally, however, has been histologically localized first within the tubular lumen and later in tubular cells providing the major evidence in favor of the concept (2-6).

In the following study labeled proteins were injected into proximal and distal tubules, and the percentage recovered in ureteral urine was measured in order to more directly investigate the characteristics of the

Received for publication 31 January 1969 and in revised form 14 August 1969. absorption mechanism. The data confirm that proteins are absorbed along the proximal tubule and to a smaller extent distally. Two smaller proteins were absorbed to a greater extent than human serum albumin, and the percentage absorption of each protein was constant when the injectate concentration was varied.

\section{METHODS}

Female Sprague-Dawley rats, 200-320 g, were anesthetized with sodium pentobarbital, $50 \mathrm{mg} / \mathrm{kg}$ body weight, and diuresis was produced by infusing $10 \%$ mannitol in $0.9 \%$ $\mathrm{NaCl}$ at $0.194 \mathrm{ml} / \mathrm{min}$. The left kidney was exposed for micropuncture through an abdominal incision, and it was supported in a plastic cup.

The injection procedure was similar to those previously reported $(6-8)$. The protein concentration of the injectate was adjusted and approximately $10 \mu \mathrm{l}$ was placed on the bottom of a siliconized glass dish. A few crystals of Lissamine Green dye were added to this drop, and constant volumes of approximately $20 \mathrm{nl}$ were placed in droplets around the dish. The droplets were drawn into micropipettes and were either injected into proximal or distal segments of surface nephrons, or directly into counting tubes to measure the amount of radioactivity injected.

The injections lasted about $30 \mathrm{sec}$, and the entire nephron cleared of dye within about 2 min after proximal injection. The percentage of the injected radioactivity appearing in ureteral urine during the subsequent 10 min was determined with a crystal scintillation counter, and the injection sites were located by microdissection after termination of the experiment.

Several ${ }^{18 I}$ I-labeled substances were obtained from Abbott Laboratories: sodium iothalamate mol wt 536, whose renal clearance in man is similar to that of inulin (9), radioiodinated human serum albumin (RISA) mol wt 69,000, pork insulin mol wt 6000 , and $\mathrm{Na}^{181} \mathrm{I}$. The RISA was diluted with saline to 20,40 , or $100 \mathrm{mg} / 100 \mathrm{ml}$. The pork insulin was used in concentrations of $0.09 \mathrm{mg} / 100 \mathrm{ml}$ and in some experiments concentrated to $40 \mathrm{mg} / 100 \mathrm{ml}$ with nonradioactive pork insulin.

Ribonuclease A (RNAase mol wt 13,683) was obtained from Worthington Biochemicals Corporation, and was labeled with 181 I with the method described by Donovan (10), using a triiodide concentration of $12 \mathrm{mCi} / \mathrm{ml}$. The specific activity was lower than that of the other substances, and approximately $100-\mathrm{nl}$ samples of RNAase solution were injected in 1-2 min rather than the smaller volume in $30 \mathrm{sec}$. 


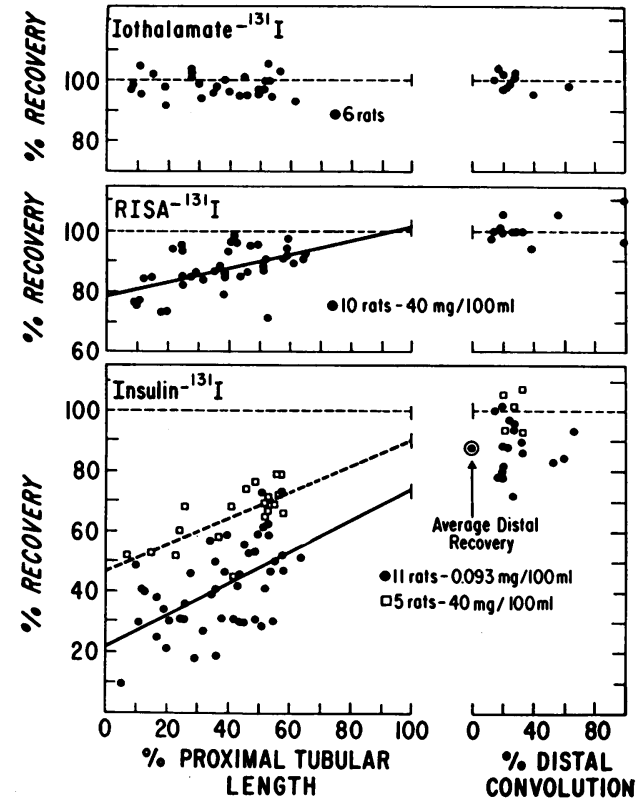

Figure 1 Percentage recovery in ureteral urine after injection into surface convolutions of : $(a)$ sodium iothalamate- ${ }^{131} \mathrm{I}$, (b) human serum albumin- ${ }^{131} \mathrm{I}, 40 \mathrm{mg} / 100 \mathrm{ml}$, and (c) pork insulin ${ }^{131} \mathrm{I}, 40 \mathrm{mg} / 100 \mathrm{ml}$ and $0.09 \mathrm{mg} / 100 \mathrm{ml}$. The regression lines are calculated by the method of least squares.

Tests of the iodinated protein indicated a molecular weight of 14,260 and negligible enzymatic activity. ${ }^{1}$

\section{RESULTS}

Iothalamate. Fig. 1 shows the recoveries obtained from injection of 38 sodium iothalamate samples into proximal and distal convoluted tubules. The recovery averaged $99 \%$ of that injected, with a standard deviation of $\pm 4 \%$ indicating that our techniques yielded complete recovery with a nonabsorbable substance. The standard deviation for samples placed directly into counting tubes was $\pm 2 \%$.

Albumin, $40 \mathrm{mg} / 100 \mathrm{ml}$. The recoveries from 51 injections of RISA in a concentration similar to that commonly suggested for glomerular fluid (11) are shown in Fig. 1. The proximal data were assumed to describe a straight line which was calculated by the least squares method. It is described by the equation $Y=0.22 X+78(Y=\mathrm{m} X+\mathrm{b})$ when $Y=\%$ recovery and $X=\%$ proximal tubular length. The slope $(\mathrm{m})$ and the $Y$ intercept $(b)$ as well as the correlation coefficient

\footnotetext{
${ }^{1}$ We are indebted to Dr. G. F. Lata and other members of the Department of Biochemistry at the University of Iowa College of Medicine for determination of the enzymatic activity of our iodinated ribonuclease, and for assistance with ultracentrifugation analysis of molecular weight.
}
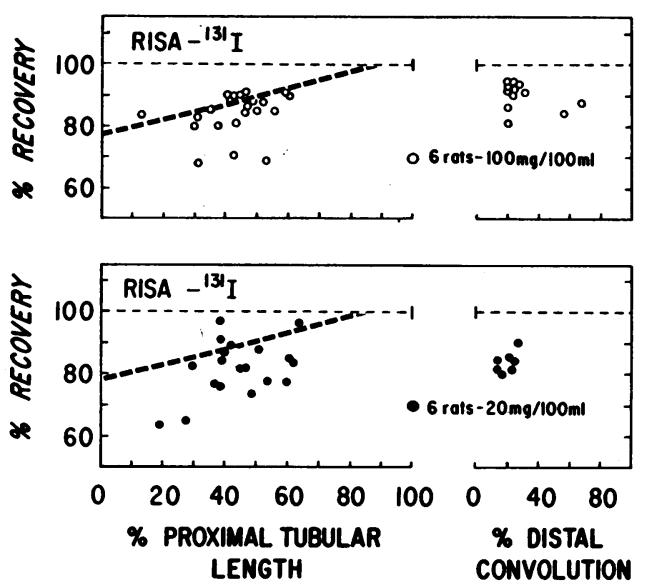

FIGURE 2 Percentage recovery in ureteral urine after injection into surface convolutions of : $(a)$ human serum albu$\mathrm{min}, 100 \mathrm{mg} / 100 \mathrm{ml}$, and $(b)$ human serum albumin, 20 $\mathrm{mg} / 100 \mathrm{ml}$. The regression lines fit the RISA $40 \mathrm{mg} / 100$ $\mathrm{ml}$ points.

( $r$ ) and statistical comparison of the values for the various experiments are shown in Table I. The probability of obtaining the correlation coefficient for RISA by chance was less than $1 \%, P_{r}<0.01$.

The intercept of $78 \%$ indicates that $22 \%$ of the injected label would have been absorbed had the volume traversed the entire nephron. The $100 \%$ recovery calculated by extrapolating the line to $100 \%$ of the proximal tubular length indicates $0 \%$ absorption by more distal parts of the nephron. The $100 \%$ recovery of samples injected into distal convoluted tubules also indicates no significant absorption by the distal parts of the nephron.

Insulin. The recoveries from both dilute $(0.09 \mathrm{mg} /$ $100 \mathrm{ml})$ and concentrated $(40 \mathrm{mg} / 100 \mathrm{ml})$ insulin solutions are given in Fig. 1. The solid dots show recoveries from 48 injections of the dilute insulin solution into proximal tubules and 17 injections into distal tubules. The least squares regression line for the proximal tubule is described by the equation $Y=0.52 X+22$, and the probability of obtaining the correlation coefficient by chance was less than $0.1 \%, P_{r}<0.001$.

The $22 \%$ recovery calculated by extrapolating the line to $0 \%$ proximal tubular length indicated that $78 \%$ of the injected insulin would have been absorbed when the volume traversed the entire nephron. The $74 \%$ recovery calculated by extrapolating the line to $100 \%$ of the proximal tubular length indicated that $26 \%$ of the injected label could be absorbed in the more distal portions of the nephron. The average recovery of 17 injections into distal convoluted tubules was $88 \%$, and this indicates that $12 \%$ of the injected label could be absorbed in the distal tubule and collecting duct.

The open squares in this figure show the recoveries from 19 injections of concentrated insulin solution into 
TABLE I

Statistical Comparison of Data

\begin{tabular}{lccccccc}
\hline Solution... & $\mathrm{mg} / 100 \mathrm{ml}$ & $r$ & $P_{r}$ & $\mathrm{~m}$ & $P_{\mathrm{m}}$ & $\mathrm{b}$ & $P_{\mathrm{b}}$ \\
\hline Insulin-131 & 0.09 & 0.57 & $<0.001$ & 0.52 & $>0.500^{*}$ & 22 & $0.005^{*}$ \\
Insulin-131 & 40 & 0.70 & $<0.010$ & 0.42 & & 48 & \\
RISA-131 & 40 & 0.50 & $<0.010$ & 0.22 & $<0.001^{*}$ & 78 & $<0.001^{*}$ \\
RISA-131I & 20 & & & 0.33 & $>0.400 \ddagger$ & 67 & $>0.200 \ddagger$ \\
RISA-131I & 100 & & & 0.18 & $>0.500 \ddagger$ & 76 & $>0.500 \ddagger$ \\
Na & 0.16 & 0.77 & $<0.001$ & 0.80 & $<0.005^{*}$ & 30 & \\
RNAase-131I & 40 & 0.57 & $<0.050$ & 0.37 & $>0.500^{*}$ & 56 & $>0.200^{*}$
\end{tabular}

Statistical comparison of data obtained from the regression lines, $Y=\mathrm{m} X+\mathrm{b}$, when $Y=\%$ recovery, $X=\%$ proximal tubular length.

* Compared with insulin $(40 \mathrm{mg} / 100 \mathrm{ml})$.

† Compared with RISA (40 mg/100 ml).

For tables of the data, order NAPS Document 006213 from ASIS National Auxiliary Publications Service, \% CCM Information Sciences, Inc., 909 Third Avenue, New York 10022, remitting \$1.00 for microfiche or $\$ 3.00$ for photocopies.

proximal tubules and five injections into distal tubules. A regression line for the proximal tubule is described by the equation $Y=0.42 X+48$, and as shown in Table $I$, the slopes of the two lines are not significantly different, $P_{\mathrm{m}}>0.5$. Absorption of the concentrated insulin solution along the entire nephron would account for $52 \%$ of the injected label, as indicated by the calculated b value of $48 \%$, and absorption in more distal portions would account for $10 \%$ of the label, since the extrapolated value at $100 \%$ of the proximal tubular length is $90 \%$ recovery. Complete recovery was obtained after injection of this concentrated solution into distal convoluted tubules indicating negligible absorption along the distal tubule and collecting duct.

The $Y$ intercept of the $40 \mathrm{mg} / 100 \mathrm{ml}$ insulin data is lower and significantly different from that of the RISA data, $P_{\mathrm{b}}<0.001$. This greater absorption of insulin by the entire nephron than of RISA is calculated using a weight/volume concentration, and if calculated on a molar basis is at least fourfold greater since the RISA molecule is larger than that of insulin. The slopes are also significantly different, $P_{\mathrm{m}}<0.001$.

Albumin, 20 and $100 \mathrm{mg} / \mathrm{ml}$. Fig. 2 shows the recoveries obtained with injections of $20 \mathrm{mg} / 100 \mathrm{ml}$ and $100 \mathrm{mg} / 100 \mathrm{ml}$ RISA solutions. The calculated regression lines for these points are $Y=0.33 X+67$ and and $Y=0.18 X+76$, respectively. The points appear to coincide with the regession line for the $40 \mathrm{mg} / 100 \mathrm{ml}$ RISA data, which is shown in the figure, and differences in the slopes and intercepts are not statistically significant (see Table I). Fractional absorption of albumin along the proximal tubule was thus similar with injectate concentrations of 20,40 , and $100 \mathrm{mg} / 100 \mathrm{ml}$. The distal recoveries averaged $85 \%$ and $90 \%$ for the 20 and 100 $\mathrm{mg} / 100 \mathrm{ml}$ samples respectively.
Ribonuclease. The recoveries obtained from 14 proximal and six distal injections of RNAase are shown in Fig. 3. The regression line for the proximal tubule is described by the equation $Y=0.37 X+56$, and the slope and intercept are not significantly different from that of the concentrated insulin line of regression. Data from distal injections are too few for certainty, but it appears as if the distal tubule did not absorb RNAase.

Sodium iodide. The recoveries from 21 proximal and six distal injections of sodium iodide are shown in Fig. 3. The regression line along the proximal tubule can be described by the equation $Y=0.80 X+30$, and the slope is significantly different from that of insulin, $P_{\mathrm{m}}<$ 0.005. The entire curve is higher than that of dilute insulin indicating less absorption of iodide at any given injection site than of dilute insulin.

The possibility that loss of label was a result of free iodide absorption was checked by testing the injectates for iodide. All protein labels passed through a Bio-Gel P-2 column rapidly, and the radioactivity peaked sharply with less than $2 \%$ in later fractions. Trichloroacetic acid precipitation of samples from a single experiment indicated that less than $3.6 \%$ of the injectate label and less than $2.5 \%$ of the urine label was filterable.

\section{DISCUSSION}

The data presented confirm that proteins can be removed from the tubular fluid as it flows along the nephron. Fractional absorption of RISA was constant with the range of concentrations used, and if loading: with albumin through the wall of the tubule is similar to normal loading by glomerular filtration, these data. suggest that fractional absorption could normally be constant over a wide filtered albumin load.

Renal Protein Absorption 

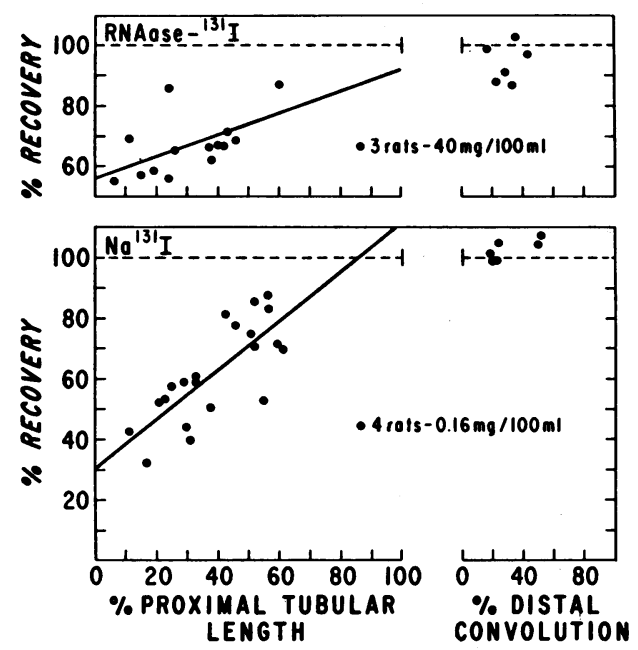

FIGURE 3 Percentage recovery in ureteral urine after injection of (a) ribonuclease $\mathrm{A}^{-181} \mathrm{I}$, and $(b) \mathrm{Na}^{181} \mathrm{I}$. The regression lines are calculated by the method of least squares for each corresponding group.

The slope of the regression line for insulin is steeper than that for RISA indicating greater absorption for each unit of proximal tubular length, and the $Y$ intercept of 22 at $0 \%$ proximal tubular length indicates that more insulin than albumin was absorbed by the entire nephron. The lower recovery at $100 \%$ proximal tubular length indicates that more insulin than albumin was absorbed within the loop of Henle. Proximal absorption of insulin was greater than albumin, however, even when correction is made for this difference in loop absorption.

The data from distal injections indicate that the distal convolution and collecting duct can absorb small quantities of insulin when injected at a concentration of 0.09 $\mathrm{mg} / 100 \mathrm{ml}$, but only negligible amounts at $40 \mathrm{mg} / 100 \mathrm{ml}$. This difference between the absorption of dilute and concentrated insulin solutions in the distal part of the nephron is similar to the difference in their absorption along the proximal tubule, and the lower recovery of dilute insulin is most likely a result of significant fractional absorption in the distal tubule. The proximal recovery curves do in fact superimpose when this correction is made. The fraction of the injected amount absorbed along the proximal tubule is thus equivalent with injectate concentrations of $0.09 \mathrm{mg} / 100 \mathrm{ml}$ or 40 $\mathrm{mg} / 100 \mathrm{ml}$.

The absorption patterns of ribonuclease and insulin were similar, and the process of removal was more complete for these smaller proteins than for albumin, contrary to the predictions of the concept of "nonselective absorption" as suggested by Hardwicke and Squire (12). Although any specific relationship between protein structure and quantitative absorption needs further investigation, the above interpretation seems evident.

This study thus presents an adaptation of previous microinjection techniques for studying tubular absorption. Absorption of protein was observed with these techniques, and qualitative relations between absorption and protein size are evident. Also, unlike the micropuncture collection experiments in which protein concentration along the proximal tubule did not vary ( 1 , 13), progressive absorption along the nephron is observed directly in the present study.

\section{ACKNOWLEDGMENTS}

This research was supported by a grant from the Iowa Heart Association, and by Public Health Service Grant AM-09323 from the National Institutes of Arthritis and Metabolic Diseases.

\section{REFERENCES}

1. Dirks, J. H., J. R. Clapp, and R. W. Berliner. 1964. The protein concentration in the proximal tubule of the dog. J. Clin. Invest. 43: 916.

2. Oliver, J., M. MacDowell, and Y. C. Lee. 1954. Cellular mechanisms of protein metabolism in the nephron. I. The strutural aspects of proteinuria; tubular absorption, droplet formation, and the disposal of proteins. J. Exp. Med. 99: 589.

3. Mendel, D. 1959. Tubular reabsorption of protein in the rat. J. Physiol. (London). 148: 1.

4. Rather, L. J. 1952. Filtration, resorption, and excretion of protein by the kidney. Medicine. 31: 357.

5. Beck, L. V., and N. Fedynskyj. 1967. Evidence from combined immunoassay and radioautography procedures that intact insulin- ${ }^{125} \mathrm{I}$ molecules are concentrated by mouse kidney proximal tubule cells. Endocrinology. $81: 475$.

6. Maunsbach, A. B. 1965. Absorption of $I^{125}$-labeled homologous albumin by rat kidney proximal tubule cells. A study of microperfused single proximal tubules by electron microscopic autoradiography and histochemistry. J. Ultrastruct. Res. 15: 197.

7. Marsh, D., and C. Frasier. 1965. Reliability of inulin for determining volume flow in rat renal cortical tubules. Amer. J. Physiol. 209: 283.

8. Bergeron, M., and F. Morel. 1969. Amino acid transport in rat renal tubules. Amer. J. Physiol. 216: 1139.

9. Sigman, E. M., C. M. Elwood, and F. Knox. 1966. The measurement of glomerular filtration rate in man with sodium iothalamate ${ }^{181}$ I (Conray). J. N.ucl. Med. 7: 60.

10. Donovan, L. G. 1962. Location of normal and abnormal tyrosyl residues in ribonuclease. Biochim. Biophys. Acta. 78: 474.

11. Pitts, R. F. 1968. In Physiology of the Kidney and Body Fluids; An Introductory Text. Year Book Medical Publishers Inc., Chicago. 2nd Edition. 86.

12. Hardwicke, J., and J. R. Squire. 1955. The relationship between plasma albumin concentration and protein excretion in patients with proteinuria. Clin. Sci. 14: 509.

13. Van Liew, J. B., and J. W. Boylan. 1969. Micropuncture study of the effect of renin on proteinuria in the rat. Fed. Proc. 28: 523. (Abstr.) 